\title{
Subacute sclerosing panencephalitis after drug-induced immunosuppression
}

\author{
J. B. S. COULTER, NICOLA BALCH, AND P. V. BEST \\ Departments of Child Health and Pathology, University of Aberdeen
}

\begin{abstract}
SUMMARY A girl developed subacute sclerosing panencephalitis (SSPE). Eight years earlier she had had measles infection contracted shortly after cytotoxic treatment and radiotherapy for a spinal neuroblastoma. The case illustrates that typical SSPE, like immunosuppressive measles encephalopathy, can arise after drug-induced immunosuppression, and supports the view that these diseases probably represent opposite ends of a spectrum induced by measles virus infection in an individual with some form of immunological deficiency.
\end{abstract}

Immunosuppressive measles encephalopathy (IME) is the term suggested by Pullan et al. (1976) for the rapidly progressive form of measles encephalitis in children who contract measles during immunosuppressive treatment. The neurological disorder develops 5 weeks to 6 months after measles infection and was first described by Lyon (1972). One way in which subacute sclerosing panencephalitis (SSPE) differs is that the interval between measles and the encephalopathy is much longer (average 6.6 years, Bellman and Dick, 1977) and we have found only one account of an SSPE-like illness after immunosuppressive treatment (Loirat et al., 1971). We report a girl who contracted measles shortly after having received cyclophosphamide and radiotherapy for a neuroblastoma and who developed typical SSPE 8 years later.

\section{Case report}

The girl, born in Morayshire in July 1967 after an uneventful pregnancy and labour, developed paraplegia in November 1967 due to an extradural neuroblastoma at T9. She was in Adelaide, South Australia, at that time and after surgical decompression of the cord, a course of radiotherapy totalling 3500 rads was administered to a field extending from $\mathrm{T} 7$ to L4 inclusive. Cyclophosphamide was given in a dose of $3 \mathrm{mg} / \mathrm{kg}$ per day from 18 March to 27 August 1968. Treatment was interrupted twice for short periods because of neutropenia and was finally stopped owing to recurrence of neutropenia and anaemia. In late September she contracted measles from her elder sister but the illness was mild. She had not had measles immunisation.
The family returned to the UK in 1969. The patient's paraplegia was permanent and an ileal diversion was fashioned in 1971 because of urinary incontinence. Cycloserine $125 \mathrm{mg}$ daily was given from 1971 to 1977 prophylactically for urinary tract infection.

In June 1977 the girl was referred to the neurology clinic because of deterioration in school performance, and lack of co-ordination and dressing skills during the previous 4 months; before this she had made good progress at school and had walked well with the aid of crutches and calipers. The only abnormality found apart from the paraplegia was slight incoordination of the left hand. The fundi were normal. When seen in August the patient was found to have suffered further deterioration in intellectual function and was reported to have had brief 'absences' accompanied by drooping of the left side of her mouth and a tendency to fall to the left. Her left arm now had a slight tremor and was weak. Treatment with sodium valproate was begun. In October she was admitted to hospital and by then had deteriorated markedly with spasticity of both upper limbs, especially the left, myoclonic jerks on this side, and epilepsia partialis continua of the left arm and left side of the face. She died 3 weeks later, 8 months after her initial symptoms.

\section{Investigations}

Urine (July 1977) vanillylmandelic acid and catecholamines normal: 17-hydroxycorticosteroids 20 $\mu \mathrm{mol} / 24 \mathrm{~h}(5 \cdot 8 \mathrm{mg} / 24 \mathrm{~h}), 17$-ketosteroids $9 \mu \mathrm{mol} / 24$ h $(2.6 \mathrm{mg} / 24 \mathrm{~h})$. Skull and chest $x$-rays normal. CAT brain scan (September 1977) showed dilatation of the 4th ventricle and slight enlargment of the pontine cisterns and cisterna magna, the appearances suggesting cerebellar atrophy. Blood (October 1977) $\mathrm{Hb} 11.8 \mathrm{~g} / \mathrm{dl}$, WBC $4.8 \times 10^{9} / 1$ with normal differential, urea $6.6 \mathrm{mmol} / 1(39.6 \mathrm{mg} / 100 \mathrm{ml})$, electrolytes normal. Measles serum complement fixation titre (CFT) 1:16 384; IgM specific for measles $1: 12$. Serum immunoglobulins: IgG $12 \cdot 0$ $\mathrm{g} / \mathrm{l}, \operatorname{IgA} 2 \cdot 4 \mathrm{~g} / \mathrm{l}$, IgM $2.5 \mathrm{~g} / \mathrm{l}$. Plasma cortisol at 2200 hours $760 \mathrm{nmol} / 1(27 \mu \mathrm{g} / 100 \mathrm{ml})$, at 0800 hours $680 \mathrm{nmol} / \mathrm{l}(25 \mu \mathrm{g} / 100 \mathrm{ml})$. CSF cells normal, protein $0.44 \mathrm{~g} / 1$ (44 mg/100 ml), IgG 0 $108 \mathrm{~g} / 1(10.8 \mathrm{mg} / 100$ $\mathrm{ml}$ ), measles CFT 1:128. EEG showed a generalised high voltage theta/delta wave activity with periodic 
higher voltage slow wave complexes, which at times had a notched appearance, occurring every 5-6 seconds; these arose predominantly over the right hemisphere initially but were more symmetrical in a later EEG.

\section{Necropsy}

Both legs were severely wasted and there was pronounced kyphoscoliosis. The ileal bladder contained a small amount of clear urine which readily refluxed into dilated ureters and there was bilateral hydronephrosis. Histological studies showed chronic pyelonephritis, centrilobular liver cell necrosis, and bronchopneumonia. Neither local recurrence of neuroblastoma nor metastases was identified. The lower lumbar and sacral regions of the spinal cord were completely atrophic and immediately above this area $a 1.5 \mathrm{~cm}$ length of the upper lumbar cord was slightly expanded by greyish gliosis. The brain was externally unremarkable but transection after fixation showed slight induration and pinkish grey

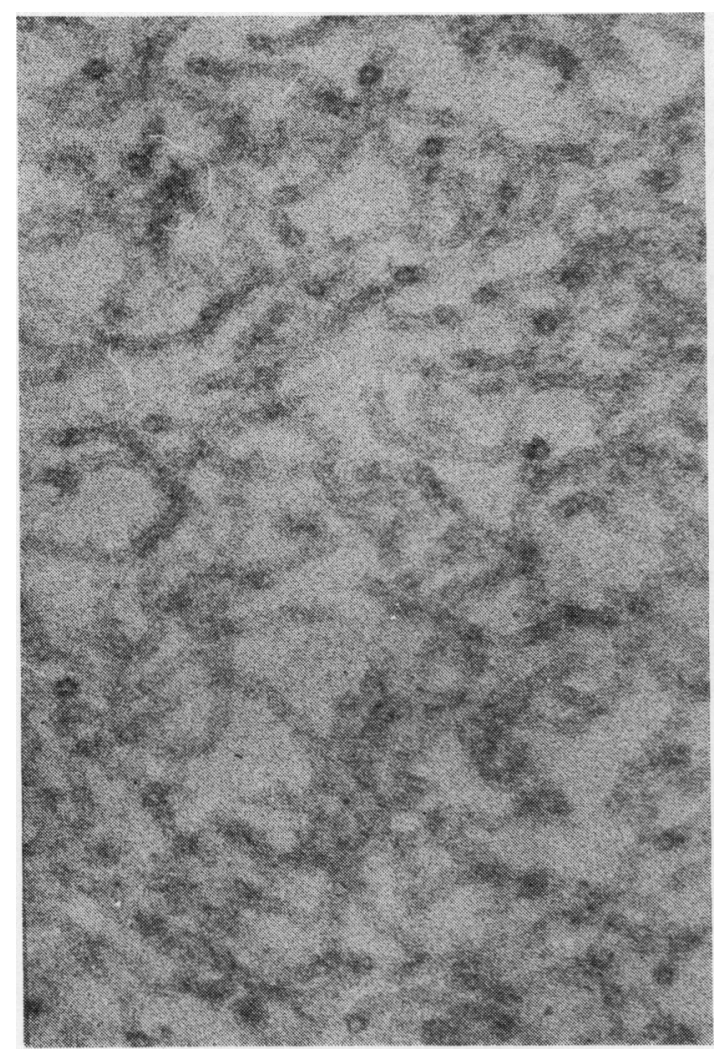

Figure Electron micrograph showing intranuclear microtubules. $\times 128000$. discoloration of the cerebral white matter, especially in the occipital lobes.

The histological features of the brain were typical of SSPE with extensive subacute inflammatory changes affecting both grey and white matter. The main characteristics were perivascular cuffing by small mononuclear cells, mainly lymphocytes, depletion of myelinated fibres in white matter accompanied by conspicuous astrocytic gliosis, degeneration and fall-out of neurones, with various degrees of reactive microglial proliferation and frequent intranuclear eosinophilic inclusion bodies mostly in oligodendrocytes. Electron microscopy showed intranuclear tubular structures indistinguishable from paramyxovirus nucleocapsids (Figure).

\section{Discussion}

The clinical diagnosis of SSPE in this case was suggested by the history of slowly progressive symptoms with prominence of mental deterioration followed by involuntary movements and myoclonus before there was major loss of cortical function. The EEG with periodic complexes at 5-6 seconds superimposed upon a generalised abnormality supported this.

In contrast, a review of the 20 cases of IME so far reported shows that this condition often starts with unilateral seizures progressing to generalised seizures and hemiplegia; occasionally there may be myoclonic jerks, epilepsia partialis continua, and involuntary movements. The progression from somnolence to coma may be very rapid, with death in several cases as early as 2-8 weeks after onset of symptoms. Except for 3 patients who survived with neurological damage, all have died within 5 months of onset. The EEG usually has a generalised abnormality often with focal discharges.

The CSF in IME is usually normal although there may be a slight increase in protein and cell count. The pronounced increase in IgG in our case is typical of SSPE. High measles antibody titre occurs in serum and CSF in both conditions and the measles virus has now also been isolated from the brain in IME (Aicardi et al., 1977). A high level of measles-specific IgM in the CSF has so far been recorded only in SSPE, and in our patient it was 1:12.

In a comparison of the pathological changes in SSPE and IME, several reports of the latter have drawn attention to a singular lack of perivascular cuffing by inflammatory cells. This has, however, been present in most cases. Inclusion bodies and astrocytic gliosis typical of SSPE are also almost always noted in IME although microglial proliferation is somewhat less constant. Thus there is not a clear histopathological distinction from SSPE and 
the differences observed may largely depend on the duration of the disease.

SSPE and IME may well represent opposite ends of a spectrum of disease induced by measles virus persisting in the brain, and the nature and severity of immunological deficiency at the time of the initial infection may determine the latent period and rate of progress of the encephalitis. Various immunological abnormalities have been found in patients with SSPE (Addy, 1977) but proof that they were present when primary infection occurred and predisposed to the 'slow' virus infection is lacking. Our patient contracted measles when there were good reasons to suspect that cell-mediated immunity was still depressed: the exanthem appeared 3-4 weeks after cyclophosphamide treatment had been stopped because of neutropenia, and the girl received radiotherapy which has been shown to prolong druginduced immunosuppression (Campbell et al., 1973). Typical SSPE began 8 years later.

The only similar recorded case was that of Loirat et al. (1971); during immunosuppressive treatment for the nephrotic syndrome, this boy developed an exanthema suggestive of measles and he died 2 years later of an SSPE-like illness during which the serum measles antibody rose to a high titre. Necropsy was not performed.

We thank Dr E. McKay for his comments and permission to report details of the patient under his care, and Dr A. W. Downie for advice.

\section{References}

Addy, D. P. (1977). Subacute sclerosing panencephalitis: microbiological aspects. Developmental Medicine and Child Neurology, 19, 69-71.

Aicardi, J., Goutieres, F., Ansenio-Nunes, M-L., and Lebon, P. (1977). Acute measles encephalitis in children with immunosuppression. Pediatrics, 59, 232-239.

Bellman, M. H., and Dick, G. (1977). Register of cases of subacute sclerosing panencephalitis. British Medical Journal, 1, 430-431.

Campbell, A. C., Hersey, P., MacLennan, I. C. M., Kay, H. E. M., Pike, M. C., and the Medical Research Council's Working Party on Leukaemia in Childhood (1973). Immunosuppressive consequences of radiotherapy and chemotherapy in patients with acute lymphoblastic leukaemia. British Medical Journal, 2, 385-388.

Loirat, C., Danon, F., and Broyer, M. (1971). Panencéphalite subaiguë sclerosante survenant au cours d'un syndrome nephrotique traite par les immunosuppresseurs. Archives françaises de pédiatrie, 28, 1083-1091.

Lyon, G. (1972). Examen ultra-structural du cerveau dans trois encéphalopathies aiguës et chroniques. Archives françaises de pédiatrie, 29, 641-654.

Pullan, C. R., Noble, T. C., Scott, D. J., Wisniewski, K., and Gardner, P. S. (1976). Atypical measles infections in leukaemic children on immunosuppressive treatment. British Medical Journal, 1, 1562-1565.

Correspondence to Dr Nicola J. Balch, Department of Pathology, University Medical Buildings, Foresterhill, Aberdeen AB9 2ZD.

\section{Response of neonatal hypocalcaemia to $1 \alpha$-hydroxyvitamin D3}

\section{Y. BARAK, B. MILBAUER, Y. WEISMAN, S. EDELSTEIN, AND Z. SPIRER \\ Division of Paediatrics, and the Vitamins Research Laboratory, Municipal Governmental Medical Centre, Tel Aviv}

SUMMARY Administration of $1 \alpha-\mathrm{OH}-\mathrm{D} 3$ to hypocalcaemic neonates (mean $\pm \mathbf{S D}$, serum calcium $1 \cdot 50 \pm 0 \cdot 13 \mathrm{mmol} / \mathrm{l}$ ) significantly increased serum calcium in all 24 infants within 48 hours after starting therapy (mean \pm SD $1.83 \pm 0.23 \mathrm{mmol} / \mathrm{l}$ ). The time required to correct hypocalcaemia was significantly shorter $(2.04 \pm 0.56$ days $)$ in infants treated with $1 \alpha-\mathrm{OH}-\mathrm{D} 3$, than in 24 infants treated with calcium gluconate infusions $(4 \cdot 12 \pm 1 \cdot 0$ days). Treatment with $1 \alpha-\mathrm{OH}-\mathrm{D} 3$ was effective, easy to maintain, and produced no side effects.

Decreased parathyroid hormone (PTH) secretion and/or end organ response, increased serum calcitonin concentrations, and defects in vitamin D metabolism have been implicated in the pathogenesis of neonatal hypocalcaemia (Tsang et al., 1976).
$1 \alpha, 25$-Dihydroxyvitamin $\mathrm{D}\left(1 \alpha, 25(\mathrm{OH})_{2} \mathrm{D}\right)$, the biologically active metabolite of vitamin $\mathrm{D}$, which stimulates intestinal calcium transport, is synthesised by successive hydroxylation of vitamin D in the liver and kidney (DeLuca, 1976). Derangements in these metabolic pathways, and maternal vitamin $\mathbf{D}$ deficiency during pregnancy, may well be important factors in the pathogenesis of neonatal hypocalcaemia (Hillman and Haddad, 1975; Weisman et al., 1976; Hillman et al., 1977). We, therefore, investigated the effect of $1 \alpha$-hydroxyvitamin D3 (1 $\alpha-\mathrm{OH}-\mathrm{D} 3)$, a readily synthesised and commercially available analogue of $1 \alpha, 25(\mathrm{OH})_{2} \mathrm{D}_{3}$, in the treatment of neonatal hypocalcaemia.

\section{Patients and methods}

48 infants (mean gestational age $33 \cdot 5 \pm 2 \cdot 8, \pm \mathrm{SD}$ 